\title{
Potentiostatic Testing of Oxygen Reduction on Polymer Carbon Electrodes
}

\author{
C. A. C. Sequeira and D. M. F. Santos \\ ICEMS and Instituto Superior Técnico, TU Lisbon, Av. Rovisco Pais, 1049-001 Lisboa, Portugal \\ Correspondence should be addressed to C. A. C. Sequeira, cesarsequeira@ist.utl.pt \\ Received 16 May 2011; Revised 2 August 2011; Accepted 4 August 2011 \\ Academic Editor: Milan M. Jaksic
}

Copyright $\odot 2011$ C. A. C. Sequeira and D. M. F. Santos. This is an open access article distributed under the Creative Commons Attribution License, which permits unrestricted use, distribution, and reproduction in any medium, provided the original work is properly cited.

The preparation of polymer carbon electrocatalysts by the controlled pyrolysis of polyfurfuryl alcohol polymer is described. Potentiostatic testing in oxygen-saturated $\mathrm{KOH}$ electrolytes is performed, and electrokinetic properties of the electrodes prepared from the electrocatalysts are presented and discussed. It is revealed that a pure polymer carbon electrode pyrolysed in powder form possesses a very high active area, displaying higher catalytic activity than a polymer pyrolysed in bulk. Suitable reduction mechanisms are proposed.

\section{Introduction}

The four-electron reduction of oxygen in either acid or alkaline solution is of primary concern due to its possible use in fuel cells and metal-air batteries on the basis of its high theoretical equilibrium potential of $1.229 \mathrm{~V}$ versus a hydrogen electrode in the same solution.

The majority of research on this reaction has centred on the use of noble metal electrodes, due to their relative stability in acidic or alkaline solutions [1-9]. Emphasis has also been placed on the study of oxygen reduction on simple carbon electrodes [10-12] and carbon electrodes containing catalysts to aid in the decomposition of the peroxide intermediates to yield the four-electron reduction process [1318]. Early research on metal chelates [19-22] has also shown that both the stability and the activity of these metal chelates could be greatly enhanced by adsorption onto a graphite or glassy carbon surface followed by a partial pyrolysis at $900^{\circ} \mathrm{C}$. It was suggested that this heat treatment resulted in the partial pyrolysis and polymerisation of the adsorbed metal chelates enhancing the activity as a result of increased stability and increased electrical conductivity. Other workers reached practically similar conclusions.

The research for this series of works was based in part on the previously observed behaviour of oxygen reduction on pure and modified carbon electrodes and on the established structure and properties of polymer (glassy) carbons [2329]. Accordingly, the oxygen reduction kinetics and mechanism determination on pure and doped polymer carbon electrodes are being conducted in our laboratory. In this paper, results and subsequent analysis of the oxygen reduction reaction on two similar polymer carbon (PC) electrodes, differing in their preparation procedure, is presented. The activity of these electrodes in comparison to that of a $\mathrm{Pt}$ electrode is also illustrated.

\section{Experimental}

2.1. Electrode Synthesis. In this study, three electrodes were used: a Pt electrode and two PC electrodes (PCA and PCB). The following procedure was developed to synthesise the PCA electrode: $40.0 \mathrm{~mL}$ of furfuryl alcohol (NR Grade) was added to a $250 \mathrm{~mL}$ vacuum flask connected to an aspirator and sitting on a stirring/heating mantle. The flask was insulated with glass wool: $0.01 \mathrm{~mL}$ of $5 \mathrm{M} \mathrm{HCl}$ was added, and the flask stoppered with a thermometer to determine the temperature of the solution. Low heat was applied under stirring until the temperature reached $55^{\circ} \mathrm{C}$. The heating was controlled so that the temperature was not allowed to rise higher than $75^{\circ} \mathrm{C}$, due to the polymerization of the liquid that releases heat. The liquid was kept at $75^{\circ} \mathrm{C}$ for at least 
one hour under constant stirring. Afterwards, a vacuum was applied by the aspirator to remove the water vapour. During evacuation, no heat was applied, and the temperature dropped below $40^{\circ} \mathrm{C}$. Then, low heat was applied to maintain the temperature at $70^{\circ} \mathrm{C}$ for $30 \mathrm{~min}$. Thereafter, the vacuum was discontinued and the polyfurfuryl alcohol resin poured into $20 \mathrm{~mL}$ test tubes with $1.25 \mathrm{~cm}$ diameter. The test tubes were then heated in an oven at a temperature of $85^{\circ} \mathrm{C}$ for $48 \mathrm{~h}$ followed by heating at $110^{\circ} \mathrm{C}$ for $24 \mathrm{~h}$. After cooling, the polymer rod could be easily removed and sliced into $1-2 \mathrm{~mm}$ thick discs with a band saw. The discs were then polished on silicon carbide papers and acetone-soaked paper. After drying, weight and area measurements were made on each disc. The polymer discs were then placed on a porcelain disc of the same diameter and placed in a small porcelain boat. The boat was then placed into a tube furnace, designed to allow thermal treatment in the temperature range of $25^{\circ} \mathrm{C}$ to $1200^{\circ} \mathrm{C}$. The heating rate was $15 \pm 1^{\circ} \mathrm{C} /$ hour with the maximum temperature set for two hours. The pyrolysis was conducted under a nitrogen flow and atmospheric pressure. Thereafter, the furnace was allowed to cool naturally to room temperature. The polymer carbon discs were then removed and area and weight measurements conducted. It was observed that the percentage of weight loss of the discs after the pyrolysis at $1200^{\circ} \mathrm{C}$ was about $30 \%$. The density, thickness, exposed area, and DC three-point conductivity of the prepared discs were about $1.53 \mathrm{~g} \mathrm{~cm}^{-3}, 0.15 \mathrm{~cm}, 0.75 \mathrm{~cm}^{2}$, and over $4 \times 10^{-2} \mathrm{mho} \mathrm{cm}^{-1}$, respectively. Each disc was then stored in a separate corked test tube.

To largely increase the area of the PC electrodes, some of the prepared polymer discs were pyrolysed to $300^{\circ} \mathrm{C}$. At this temperature, the polymer was practically pyrolysed, but was very brittle and could be powdered. Then, the pyrolysis was followed to the desired temperature, as in the procedure outlined for the PCA discs. The resulting electrocatalyst possessed a much higher active area than the polymer pyrolysed in bulk, allowing the construction of PCB electrodes from this material by compressing the electrocatalyst with a PVDF binder and baking.

2.2. Potentiostatic Testing. The electrochemical measurements were taken in a conventional three-compartment cell with PAR equipment. Each specially mounted PC served as the working electrode. The counter electrode was a $\mathrm{Pt}$ gauge, and a saturated calomel electrode served as the reference electrode. Before inserting the electrodes, the cell was precleaned by soaking in a Chromerge bath followed by washing with bidistilled water and oven dried. Then a fresh electrolyte solution $(200 \mathrm{~mL} \mathrm{KOH} \mathrm{pH} 13.9$ and $\mathrm{KOH}$ $+\mathrm{KCl}$ solutions of decreasing $\mathrm{pH}$ ) was added for each particular test. Oxygen and oxygen-nitrogen mixtures flowed continually for 4 hours to allow the solution to saturate with the gas and the working electrode to reach a stable rest potential. The potential was slowly polarized negatively until a limiting current density of about $0.1 \mathrm{~mA} \mathrm{~cm}^{-2}$ was approached.

It should be noted that the reported current densities are referred to the apparent surface area $\left(75 \mathrm{~mm}^{2}\right)$ of the PC electrodes; the real surface area, as determined from static volumetric methods, was $120 \mathrm{~m}^{2} \mathrm{~g}^{-1}$ (PCB) and $1 \mathrm{~m}^{2} \mathrm{~g}^{-1}$ (PCA). All experiments were conducted at $298 \pm 2 \mathrm{~K}$.

\section{Results and Discussion}

3.1. Determination of $\alpha, i_{0}$, and $i_{l}$. The general method of dealing with a net reaction rate, in which a limiting rate can occur, uses the following equation to derive a relation for the current density, $(i)$

$$
\left(\frac{1}{i}\right)=\left(\frac{1}{i_{\mathrm{ab}}}\right)+\left(\frac{1}{i_{l}}\right) .
$$

The term $i_{\mathrm{ab}}$ is the current density in the absence of any limiting current density, $i_{l}$. Equation (1) provides the basis for the following logical steps, since it takes into account charge transfer and diffusion steps, which commonly occur in many electrochemical processes [30, 31]. Rearranging (1) gives

$$
i=i_{\mathrm{ab}}\left[1-\left(\frac{i}{i_{l}}\right)\right] .
$$

The current density $i_{\mathrm{ab}}$ can be expressed as a function of the exchange current density, $i_{0}$, and the overpotential, $\eta$, by the following expression:

$$
i_{\mathrm{ab}}=i_{0} \exp \left(\frac{\alpha F_{\eta}}{\mathrm{RT}}\right),
$$

where $\alpha$ is the cathodic transfer coefficient. In oxygen reduction, the observed rest potentials $[10,32,33]$ are over $100 \mathrm{mV}$ cathodic to the true equilibrium potential, $E_{r}^{0}$. For this reason, the applied overpotential is large enough so that the anodic current density can be neglected in relation to the cathodic current density, as represented by (3). The overpotential, $\eta$, represents the difference between the standard equilibrium for oxygen reduction, $E_{r}^{0}$, and the potential set by the potentiostat with reference to an hydrogen electrode in the same solution $\left(E_{\mathrm{he}}\right)$ :

$$
\eta=E_{r}^{0}-E_{\mathrm{he}}
$$

Here, $\eta$ will always refer to a cathodic overpotential. Insertion of (3) into (2) followed by rearrangement yields

$$
\eta=\left(\frac{\mathrm{RT}}{\alpha F}\right) \ln \left[\frac{i}{i_{l}-i}\right]+\left(\frac{\mathrm{RT}}{\alpha F}\right) \ln \left[\frac{i_{l}}{i_{0}}\right] .
$$

Thus, it can be seen from (5) that a plot of $\eta$ as a function of $\ln \left[i /\left(i_{l}-i\right)\right]$ will give a linear relationship, with a slope of $(\mathrm{RT} / \alpha F)$ and an intercept of $(\mathrm{RT} / \alpha F) \ln \left(i_{l} / i_{0}\right)$.

This allowed for the maximum number of data points to be used in the analysis. In the normal Tafel plot of $\eta$ as a function of $\ln i$, as the current density increased to more than $10 \%$ of the limiting current density, the points would fall off the linear Tafel plot. Equation (5) allows these points to be used effectively in the analysis.

In order to use (5), it was necessary to know the limiting current density. With the potentiostatic technique employed, the limiting current density was approached but 
never actually reached experimentally. At each potential, the current was allowed to come to a steady value, but, at the point of the limiting current density (which should be constant), a steady current density was never achieved. Instead, current oscillations were observed because at $i_{l}$ the oxygen concentration drops to zero, and then there is no ionic charge to counterbalance the electronic charge imposed by the potentiostatic technique. The limiting current density was calculated in another manner using all the potentiostatic data up to the point at which oscillations were observed. These points were all steady values. With this method, the limiting current density did not have to be estimated from the graphs of the potential as a function of $\ln i$. As a starting point in this determination, an arbitrary current density slightly greater than the largest value observed experimentally was used to calculate a least squares fit of $\eta$ as a function of $\ln \left[i /\left(i_{l}-i\right)\right]$ and a corresponding correlation coefficient, $R_{c} . R_{c}$ is merely a measure of the fit of the calculated line to the data points. It could vary from -1 to +1 depending on whether the slope was negative or positive and how well the fit was. A perfect correlation would be \pm 1 . The $\ln i_{l}$ was then decreased by a small increment and another least squares fit calculated for $\eta$ as a function of $\ln \left[i /\left(i_{l}-i\right)\right]$ using the new value of $i_{l}$. If the correlation coefficient indicated a better fit, then the value of $\ln i_{l}$ was decreased again and the identical procedure followed. The $R_{c}$ value would reach a maximum absolute value of 0.97 and then begin to decrease with the decrease in $\ln i_{l}$. The value of $\ln i_{l}$ which gave the maximum absolute value for $R_{c}$ was interpreted to be the most accurate value for the actual $\ln i_{l}$ and was used to give the optimum and the most accurate value for the diffusion current density. This procedure was written into a noncommercial computer program so that the data could be analysed quickly and efficiently.

Using this optimum limiting diffusion current density, the transfer coefficient and the exchange current density could be determined from the slope $(S)$ and the $y$-intercept $(Y)$ of $\eta$ as a function of $\ln \left[i /\left(i_{l}-i\right)\right]$, also calculated by this computer program,

$$
\begin{gathered}
\alpha=\left(\frac{\mathrm{RT}}{\mathrm{SF}}\right), \\
i_{0}=i_{l} \exp \left(\frac{-\alpha F Y}{\mathrm{RT}}\right) .
\end{gathered}
$$

This computer analysis was completed for the data obtained from each potentiostatic run made for all electrodes tested.

3.2. Reaction Order with respect to $\left[\mathrm{OH}^{-}\right]$. In order to calculate the reaction orders, it was necessary to know the current density, $i$, as a function of the potential with respect to a standard hydrogen electrode $E[34,35]$ as shown by the following relation for the possible $\mathrm{O}_{2}$ reduction on the PC electrodes, yielding $\mathrm{OH}^{-}$ions:

$$
i=k\left[\mathrm{OH}^{-}\right]^{m}\left[\mathrm{O}_{2}\right]^{p} \exp \left[\frac{-\alpha F E}{\mathrm{RT}}\right] .
$$

The value of $k$ refers to the rate constant for the reaction. By taking the $\log$ of both sides of (7), the reaction order with respect to $\left[\mathrm{OH}^{-}\right], m$, can be expressed by the following derivative at constant potential, $E$, and constant $\left[\mathrm{O}_{2}\right]$ :

$$
m=\left(\frac{\partial \log i}{\partial \log \left[\mathrm{OH}^{-}\right]}\right)_{E} .
$$

This value of $m$ can also be determined from the derivative of $\log i$ with respect to $\mathrm{pH}$ at constant potential, $E$, as shown in the following equations:

$$
\begin{gathered}
\mathrm{pH}=14+\log \left[\mathrm{OH}^{-}\right], \\
\left(\frac{\partial \mathrm{pH}}{\partial \log \left[\mathrm{OH}^{-}\right]}\right)_{E}=1, \\
m=\left(\frac{\partial \log i}{\partial \log \left[\mathrm{OH}^{-}\right]}\right)_{E} \\
=\left(\frac{\partial \log i}{\partial \mathrm{pH}}\right)_{E} \times\left(\frac{\partial \mathrm{pH}}{\partial \log \left[\mathrm{OH}^{-}\right]}\right)_{E} \\
=\left(\frac{\partial \log i}{\partial \mathrm{pH}}\right)_{E}
\end{gathered}
$$

Thus, from a least squares analysis of $\log i$ as a function of $\mathrm{pH}$ at constant potential, $E$, and constant $\left[\mathrm{O}_{2}\right]$, the reaction order $m$ can be determined from the slope. It should be noted that one usually considers the inward and outward $\mathrm{O}_{2} / \mathrm{OH}^{-}$ reactions to more correctly define the reaction order, $m$, with respect to $\left[\mathrm{OH}^{-}\right]$.

Experimentally it was difficult to determine the values of the current density at the exact same potential values, $E$, for each different electrolyte $\mathrm{pH}$. It was much simpler to use the procedure outlined earlier to determine the values of $\alpha$ and $i_{0}$ by the least squares computer analysis for oxygen reduction on these electrodes in oxygen-saturated electrolytes of differing $\mathrm{pH}$. Using these parameters, the values of $\log i$ as a function of the electrolyte $\mathrm{pH}$ in which these parameters were determined could be calculated at a constant value of potential, E. A least squares analysis of these data would yield a value of $m$ at each potential $E$. The potential values were in increments of 5 to $10 \mathrm{mV}$ and were chosen to give the same range of current densities as observed experimentally in the potentiostatic analysis. The average of the orders $m$ calculated at each potential $E$ was reported as the most probable reaction order with respect to $\left[\mathrm{OH}^{-}\right]$. Calculated in this manner, most of the experimentally determined data points could be used. This varied from 40 to 120 data points, depending on the electrode being tested.

The relation necessary to calculate $\log i$ as a function of $\mathrm{pH}$ for a set potential $E$ with reference to a standard hydrogen electrode can be derived from (3) and (4). The potential with respect to a hydrogen electrode in the same electrolyte can be expressed by the following relation under constant oxygen saturation:

$$
E_{\mathrm{he}}=E+0.0591 \mathrm{pH} .
$$

Substitution of (10) into (4) yields

$$
\eta=E_{r}^{0}-E-0.0591 \mathrm{pH} .
$$


Substitution of (11) into (3) followed by taking the log of both sides yields (letting $i$ represent $i_{\mathrm{ab}}$ )

$$
\log i=\left[\frac{\alpha F}{2.30 \mathrm{RT}}\right]\left[E_{r}^{0}-E-0.0591 \mathrm{pH}+\left(\frac{\mathrm{RT}}{\alpha F}\right) \ln i_{0}\right] .
$$

Thus, from the potentiostatic data for oxygen reduction at each electrolyte $\mathrm{pH}$, analysis values for $\alpha$ and $i_{0}$ are calculated via the least squares computer analysis at the particular $\mathrm{pH}$. These can be fed into (12) for each corresponding value of $\mathrm{pH}$ and used to generate $\log i$ as a function of the $\mathrm{pH}$ for set values of potential. The value used for $E_{r}^{0}$, for oxygen reduction in an electrolyte saturated with oxygen at $1 \mathrm{~atm}$. measured with respect to a hydrogen electrode in the same electrolyte, was $1.229 \mathrm{~V}$. Any change due to the lower atmospheric pressure is accounted for by the experimental value of $i_{0}$ used in (12). This was the case since the value of the overpotential calculated from (4) used the value of 1.229 for $E_{r}^{0}$ also.

3.3. Reaction Order with respect to $\left[\mathrm{O}_{2}\right]$. This calculation was completed in much the same manner as the calculation of the reaction order with respect to $\left[\mathrm{OH}^{-}\right]$. By taking the log of both sides of (7), the reaction order with respect to $\left[\mathrm{O}_{2}\right]$, $p$, can be expressed by the following derivative at constant potential $E$ and constant $\mathrm{pH}$ :

$$
p=\left(\frac{\partial \log i}{\partial \log \left[\mathrm{O}_{2}\right]}\right)_{E, \mathrm{pH}}
$$

Since the oxygen concentration in the electrode is directly proportional to the oxygen partial pressure, the oxygen concentration was varied by dilution with nitrogen. This was controlled by measuring the flow rate of each gas before mixing. The potentiostatic analysis was performed in the $\mathrm{pH}$ range of 13.9 to 10.9 .

From the potentiostatic data at each oxygen partial pressure, the values of $\alpha$ and $i_{0}$ for each oxygen partial pressure were determined via the least squares computer analysis outlined previously. These values could then be inserted into (12) in order to calculate $\log i$ as a function of the $\log$ of the oxygen partial pressure, $\log \left[\mathrm{O}_{2}\right]$ for each set potential $E$. For each value of potential $E$, a least squares analysis was performed on the data which yielded the order of the reaction with respect to $\left[\mathrm{O}_{2}\right]$ from the slope of the function (13). The average of the orders calculated at all potential values $E$ was taken as the most probable order of the reaction with respect to $\left[\mathrm{O}_{2}\right]$.

3.4. Analysis of the Observed Rest Potentials. A limited analysis of the observed rest potentials (open-circuit potentials) for oxygen reduction on these electrodes was conducted from the data used to determine the reaction orders. This should be considered to be a rough determination of dependence of the rest potentials on $\left[\mathrm{OH}^{-}\right]$and $\left[\mathrm{O}_{2}\right]$ due to the small number of data points available. They were sufficient to indicate the dependencies though.

The observed rest potential, $E_{r}$, can be expressed as a function of the observed standard potential, $E_{r}^{0}$, the total number of electrons transferred in the reaction, $n$, the concentration $\left[\mathrm{OH}^{-}\right]$, and the oxygen partial pressure, $\left[\mathrm{O}_{2}\right]$, by the following relation, assuming that the activity coefficients are 1:

$$
E_{r}=E_{r}^{0}-\left(\frac{\mathrm{RT}}{n F}\right) \ln \left(\left[\mathrm{OH}^{-}\right]^{m^{\prime}}\left[\mathrm{O}_{2}\right]^{-p^{\prime}}\right) .
$$

Equation (14) can be rearranged to yield

$$
E_{r}=E_{r}^{0}-\left(\frac{2.3 \mathrm{RT}^{\prime}}{n F}\right) \log \left[\mathrm{OH}^{-}\right]+\left(\frac{2.3 \mathrm{RT} p^{\prime}}{n F}\right) \log \left[\mathrm{O}_{2}\right] .
$$

From (15) and (9), it can be seen that the value of $m^{\prime}$ can be determined from the derivative of the potential, $E_{r}$, with respect to the $\mathrm{pH}$, and the value of $p^{\prime}$ from the derivative of the potential $E_{r}$, with respect to the $\log \left[\mathrm{O}_{2}\right]$ values:

$$
\begin{gathered}
m^{\prime}=\left(\frac{n F}{2.3 \mathrm{RT}}\right)\left(\frac{\partial E_{r}}{\partial \mathrm{pH}}\right)_{\left[\mathrm{O}_{2}\right]}, \\
p^{\prime}=\left(\frac{n F}{2.3 \mathrm{RT}}\right)\left(\frac{\partial E_{r}}{\partial \log \left[\mathrm{O}_{2}\right]}\right)_{\mathrm{pH}} .
\end{gathered}
$$

These values should not be confused with the reaction orders $m$ and $p$. A least squares analysis is performed on the values of $E_{r}$ as a function of $\mathrm{pH}$ and the $\log \left[\mathrm{O}_{2}\right]$ in which $m^{\prime}$ and $p^{\prime}$ are determined from (16) for possible values of $n$ ranging from 1 to 4 . This value is unknown since the equilibrium potential may or may not be due to the 4 electron transfer reduction of oxygen. The possibilities are discussed below.

3.5. Calculated Mechanistic Criteria. Figure 1 shows representative oxygen reduction kinetics on the two pure polymer carbon electrodes developed in this study relative to the kinetics on a $\mathrm{Pt}$ metal electrode. The maximum pyrolysis temperature of the synthesised PCs was $1200^{\circ} \mathrm{C}$. The $\mathrm{Pt}$ electrode was obtained commercially and mounted in an arrangement similar to the PCs such that the test conditions of all the electrodes were equivalent. The kinetic analysis of oxygen reduction on this $\mathrm{Pt}$ electrode was not conducted since numerous studies have appeared in the general literature for this electrode [2]. However, the authors are aware that it would be informative for the limiting current estimation. From the analysis of the obtained potentiostatic data, it could be seen that there exists a limiting current density, $i_{l}$, of approximately $0.1 \mathrm{~mA} \mathrm{~cm} \mathrm{~cm}^{-2}$ for oxygen reduction on the PC electrodes in oxygen-saturated electrolyte. This was also the case for oxygen reduction on the shielded Pt electrode under the same conditions of oxygen saturation and $\mathrm{pH}$ (see Figure 1).

This was due to the limited diffusion of reactants to the surface. For most of the tests, the hydroxyl anion concentration was $0.83 \mathrm{M}$, decreasing to $8.3 \times 10^{-4} \mathrm{M}$ in some tests. The solubility of oxygen in a $\mathrm{KOH}$ electrolyte of $0.13 \mathrm{M}$ is approximately $9.0 \times 10^{-4} \mathrm{M}$ [36]. The reactant which is the probable cause of the limiting diffusion current density is then oxygen since the $i_{l}$ did not change as $\left[\mathrm{OH}^{-}\right]$ decreased. Then, the depletion of oxygen at the surface as 


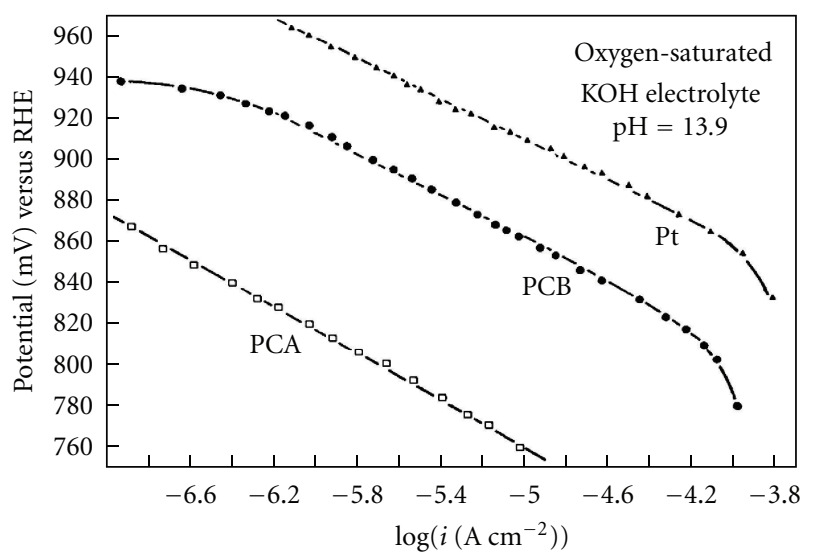

FIGURE 1: A comparison of the oxygen reduction kinetics on the prepared polymer carbon electrodes with that of a Pt metal electrode.

the rate of reduction increases results in a diffusion overpotential [34].

Plots of the applied potential as a function of $\ln \left[i /\left(i_{l}-\right.\right.$ i)], as shown in Figure 2, gave linear relationships for the oxygen reduction on the studied PCs in oxygen-saturated $\mathrm{KOH}$ electrolytes of $\mathrm{pH}$ ranging from 13.9 to 10.9.

The use of these plots, combined with (6), enabled the calculation of $\alpha, i_{0}$, and $i_{l}$. The average values for these kinetic parameters are as follows: $1.0 \pm 0.08$ for $\alpha,(1.0 \pm 0.4) \times$ $10^{-8} \mathrm{~A} \mathrm{~cm}^{-2}$ (PCA) and $(1.0 \pm 0.2) \times 10^{-6.5} \mathrm{~A} \mathrm{~cm}^{-2}(\mathrm{PCB})$ for $i_{0}$, and $(4.9 \pm 0.4) \times 10^{-5} \mathrm{~A} \mathrm{~cm}^{-2}(\mathrm{PCA})$ and $(1.3 \pm$ $0.2) \times 10^{-4} \mathrm{~A} \mathrm{~cm}^{-2}(\mathrm{PCB})$ for $i_{l}$. We recall that the transfer coefficient $\alpha$ is an experimental parameter obtained from the current-potential relationship, allowing us to evaluate the mechanism of electrode reactions or to distinguish between different plausible mechanisms. In the present case the fitted parameter $\alpha=1$ could suggest that if the anodic transfer coefficient, $\beta$ (the factor in the anodic direction), is equal to $\alpha$, then $\alpha+\beta=2$; that is, our reduction mechanism could be seen as a multistep electrode process involving the transfer of two electrons (see below). The fitted parameter $\alpha=1$ has been found by many workers as cited in [2].

Figure 3 shows the dependence of the oxygen reduction kinetics on the electrolyte $\mathrm{pH}$ for the prepared PC electrodes, and Figure 4 shows the dependence of the oxygen reduction kinetics on the oxygen partial pressure for the prepared PC electrodes in $\mathrm{KOH}$ electrolyte of $\mathrm{pH}=13.9$. In these figures, $i$ is the measured current density.

From these figures, (9) and (13), the values for $m$ and $p$ could be calculated. The results indicate that for the $\mathrm{pH}$ range of 13.9 to 10.9 , the rate kinetics for oxygen reduction on the PC electrodes can be represented by the following equation:

$$
\begin{aligned}
& \text { PCA, pH 13.9-10.9: } i=K\left[\mathrm{O}_{2}\right] \exp \left(\frac{-F E}{\mathrm{RT}}\right) \\
& \text { PCB, pH 13.9-11.9: } i=K\left[\mathrm{OH}^{-}\right]^{-1 / 2}\left[\mathrm{O}_{2}\right]^{p} \exp \left(\frac{-F E}{\mathrm{RT}}\right) .
\end{aligned}
$$

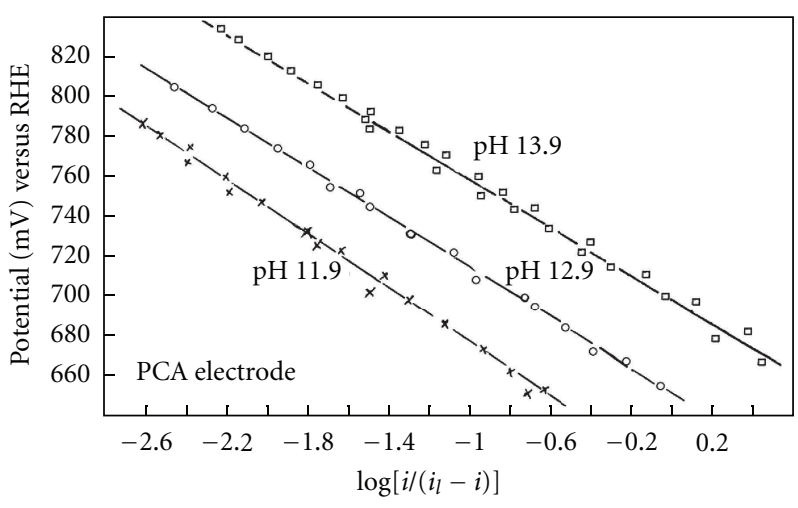

(a)

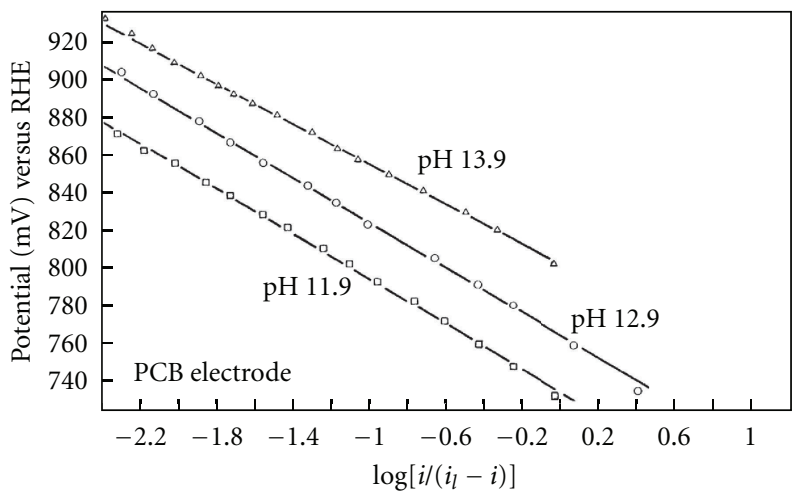

(b)

FIgURe 2: Plots of the potential as a function of $\log \left[i /\left(i_{l}-i\right)\right]$ as calculated from the oxygen reduction kinetic data for the $\mathrm{PC}$ electrodes. Oxygen-saturated $\mathrm{KOH}$ electrolyte. Constant ionic strength maintained by dilution with $1 \mathrm{M} \mathrm{KCl}$.

The value of $m$ of -0.14 is interpreted to be a reaction order of 0 . The value of $p$ was determined to be $0.28 \pm 0.06$ which can indicate an order of $1 / 3$. In other words, it was determined that on the PCA electrodes in the $\mathrm{pH}$ range of 10.9 to 13.9 and on the PCB electrodes in the $\mathrm{pH}$ range of 11.9 to 13.9 , the average values for the order of reaction with respect to $\left[\mathrm{OH}^{-}\right]$and $\left[\mathrm{O}_{2}\right]$ were 0 and 1 , respectively, for the PCA and $-1 / 2$ and $1 / 3$, respectively, for the PCB, at constant potential with respect to the SHE.

The data used to calculate the values $m^{\prime}$ and $p^{\prime}$ are plotted in Figures 5 and 6 , and possible experimental values for $m^{\prime}$ and $p^{\prime}$ are tabulated in Table 1 . In this table, the values for the rest potential, used in the calculations of $p^{\prime}$ for the PCA electrode, were obtained by extrapolating the potentiostatic data to an approximate current density of $10^{-8.4} \mathrm{~A} \mathrm{~cm}^{-2}$, since the rest potentials were somewhat unsteady. This closeto-zero value was the minimum current density above which steady potentials could be measured.

3.6. Discussion of Equilibrium Potentials. To derive what is considered to be the most probable reduction mechanism that can, at least partially, explain the oxygen reduction kinetics on the polymer carbon electrodes tested in this work, 


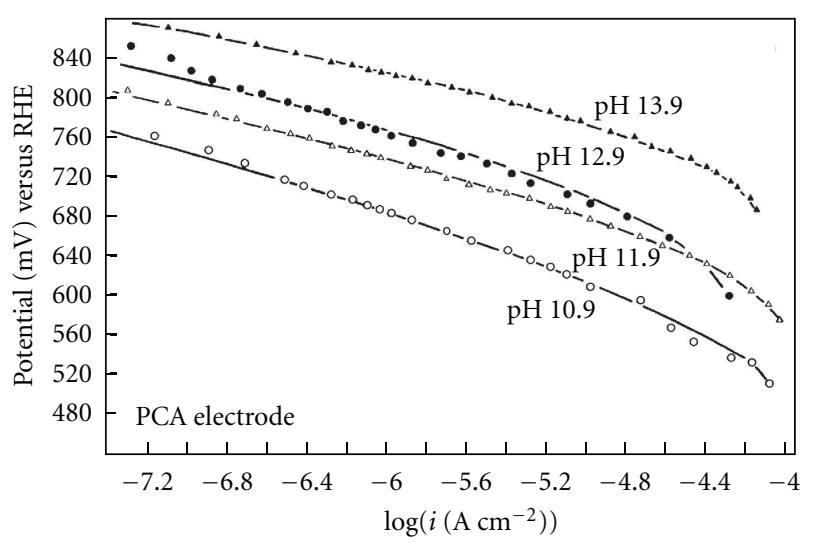

(a)

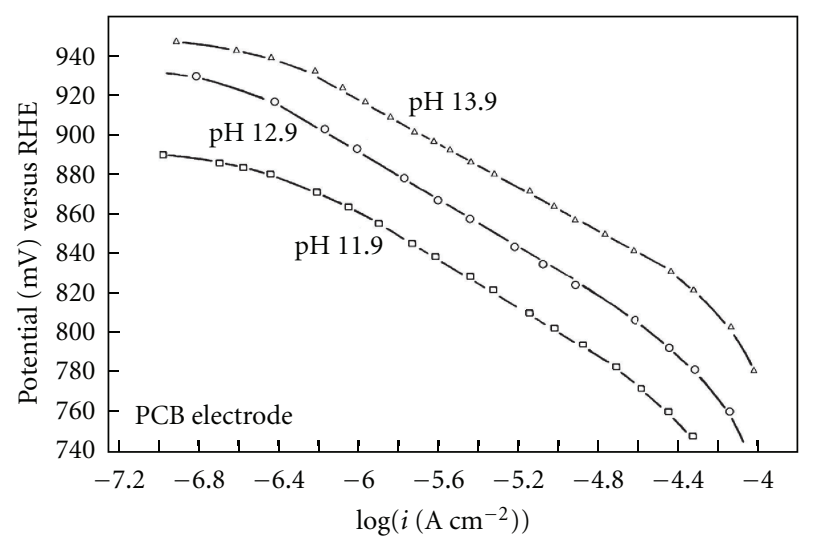

(b)

FIGURE 3: The dependence of the oxygen reduction kinetics on the electrolyte $\mathrm{pH}$ for the prepared $\mathrm{PC}$ electrodes in oxygen-saturated $\mathrm{KOH}$ electrolyte of constant ionic strength maintained by dilution with $1 \mathrm{M} \mathrm{KCl}$.

a comparison had to be performed on the experimental data and calculated parameters presented in the previous subsections with the calculated mechanistic criteria determined from all the possible mechanistic paths examined, as tabulated in a previous paper [2]. In that paper, 18 common mechanisms from the literature, with additional modifications, are analysed on the assumption that the Langmuir conditions of adsorption are obeyed. But, it should be noted that by far many other mechanisms could be postulated, namely, those which use catalysis by adsorbed hydroxyl groups under the Langmuir conditions and those using the Temkin conditions of adsorption.

In order to narrow the number of possible mechanisms, it is beneficial to examine the results concerning the equilibrium potentials for oxygen reduction on the PC electrodes in light of information from the general literature. The analysis of the equilibrium potentials was presented in Section 3.4, and the experimental results are listed in Table 1.

The first equilibrium potentials to be examined are those produced by oxygen on the least active electrode, the PCA pyrolysed in bulk. The observed equilibrium potentials could be attributed to three possible oxygen reduction reactions.

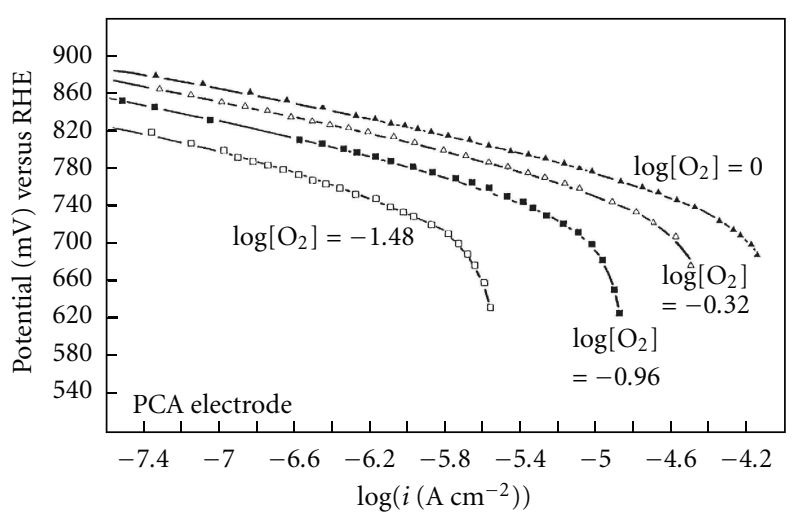

(a)

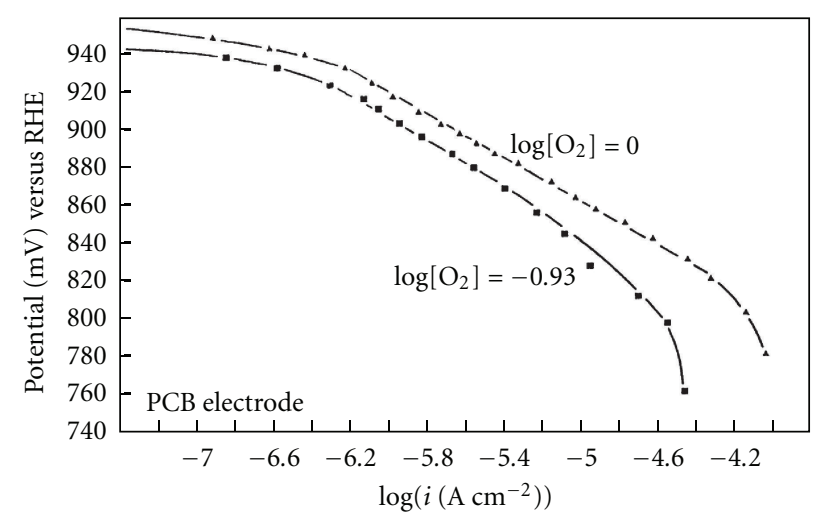

(b)

Figure 4: The dependence of the oxygen reduction kinetics on the oxygen partial pressure, $\left[\mathrm{O}_{2}\right]$, for the prepared PC electrodes in $\mathrm{KOH}$ electrolyte, $\mathrm{pH}$ 13.9.

These, in addition to the equations for the concentration dependence of the equilibrium potentials, are given by the following reactions:

$$
\begin{gathered}
\mathrm{O}_{2}+2 \mathrm{H}_{2} \mathrm{O}+4 \mathrm{e}^{-} \leftrightarrows 4 \mathrm{OH}^{-} \\
E_{r}=0.401-\left(\frac{\mathrm{RT}}{4 F}\right) \ln \left(\frac{\left[\mathrm{OH}^{-}\right]^{4}}{\left[\mathrm{O}_{2}\right]}\right) \\
\mathrm{O}_{2}+2 \mathrm{H}_{2} \mathrm{O}+2 \mathrm{e}^{-} \leftrightarrows \mathrm{H}_{2} \mathrm{O}_{2}+2 \mathrm{OH}^{-} \\
E_{r}=-0.146-\left(\frac{\mathrm{RT}}{2 F}\right) \ln \left(\frac{\left[\mathrm{H}_{2} \mathrm{O}_{2}\right]\left[\mathrm{OH}^{-}\right]^{2}}{\left[\mathrm{O}_{2}\right]}\right) \\
\mathrm{O}_{2}+\mathrm{H}_{2} \mathrm{O}+2 \mathrm{e}^{-} \leftrightarrows \mathrm{HO}_{2}^{-}+\mathrm{OH}^{-} \\
E_{r}=E_{r}^{0}-\left(\frac{\mathrm{RT}}{2 F}\right) \ln \left(\frac{\left[\mathrm{HO}_{2}^{-}\right]\left[\mathrm{OH}^{-}\right]}{\left[\mathrm{O}_{2}\right]}\right)
\end{gathered}
$$

The results listed in Table 1 show that for (15), if $n=2$, then $m^{\prime} \cong 1$ and $p^{\prime} \cong 1$, and, if $n=4$, then $m^{\prime} \cong 2$ and $m^{\prime} \cong 2$. Comparison of these results with (18), (19), and (20) shows that only (20) agrees with the experimental values for $n, m^{\prime}$, and $p^{\prime}$. Even though the experimental values should only be considered to be approximate due to the small number 


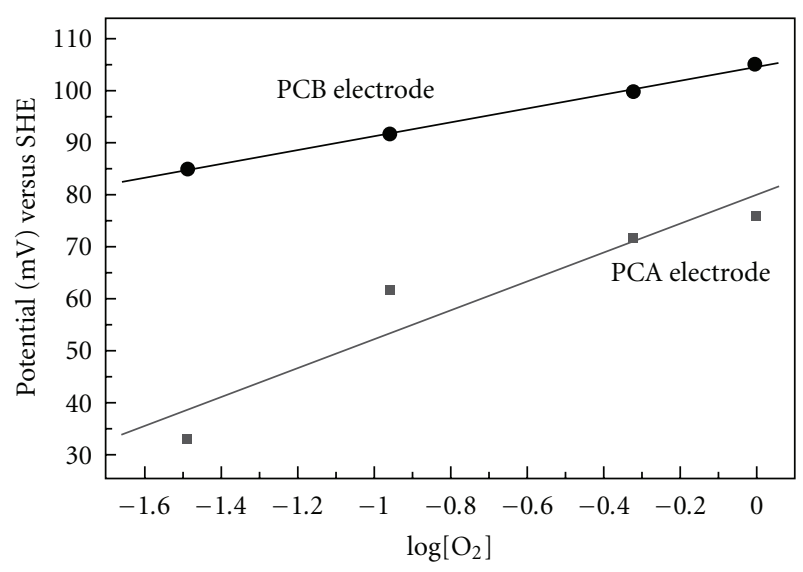

FIGURE 5: Plots of the oxygen reduction rest potentials as a function of the log of the oxygen partial pressure in $\mathrm{KOH}$ electrolyte at $\mathrm{pH}$ 13.9.

of data points, they were considered sufficient to distinguish between the three probable equilibrium reactions. Equation (20), based on the suggested net oxygen reduction reaction on the PCA electrode, is in agreement with the results of an earlier study by Taylor and Humffray [37], who used a rotating ring-disc electrode for analysis of oxygen reduction on a polymer carbon electrode. Much earlier studies by Yeager et al. [38] on oxygen reduction in alkaline electrolyte containing peroxide showed that the equilibrium could be attributed to this reaction. The only oddity here is that Yeager et al. [38] and Berl [39] found that the experimental value for $E_{r}^{0}$ was $-0.048 \mathrm{~V} / \mathrm{SHE}$ at a $\mathrm{pH}$ of 14.0 whereas the value calculated from thermodynamic data by Latimer [40] and Berl [39] was $-0.076 \mathrm{~V} / \mathrm{SHE}$ at a $\mathrm{pH}$ of 14.0.

Since no added peroxide was present in the alkaline solutions used in this study, it is interesting to calculate the equilibrium concentration of $\mathrm{HO}_{2}{ }^{-}$necessary to yield the observed equilibrium potential on the pure polymer carbon. Thus, some idea of the surface coverage of the peroxide anion can be obtained. From the previous data, the observed equilibrium potential which would occur at the $\mathrm{pH}$ of 14.0 is $0.082 \mathrm{~V} / \mathrm{SHE}$. Assuming activity coefficients of unity, the use of (20) gives

$$
\begin{aligned}
0.082 & =-0.048-(0.030) \log \left[\mathrm{HO}_{2}{ }^{-}\right] \therefore\left[\mathrm{HO}_{2}{ }^{-}\right] \\
& =4 \times 10^{-5} \mathrm{M} .
\end{aligned}
$$

This bulk concentration could then ideally correspond to a planar surface concentration of $8 \times 10^{10}$ molecules $\mathrm{HO}_{2}{ }^{-} / \mathrm{cm}^{2}$ if no concentration gradient of peroxide anions is present between the bulk solution and the surface. On the assumption of $10^{15}$ sites $/ \mathrm{cm}^{2}$ [41-44] and one $\mathrm{HO}_{2}{ }^{-}$anion per site, a surface coverage of $8 \times 10^{-5}$ is calculated for adsorbed $\mathrm{HO}_{2}{ }^{-}$. Even if a concentration gradient of 10 to 100 times the bulk concentration exists at the surface, the coverage due to $\mathrm{HO}_{2}{ }^{-}$would be less than $10^{-2}$. Thus, it is at least safe to say that the surface blockage due to this reaction intermediate would be insignificant.

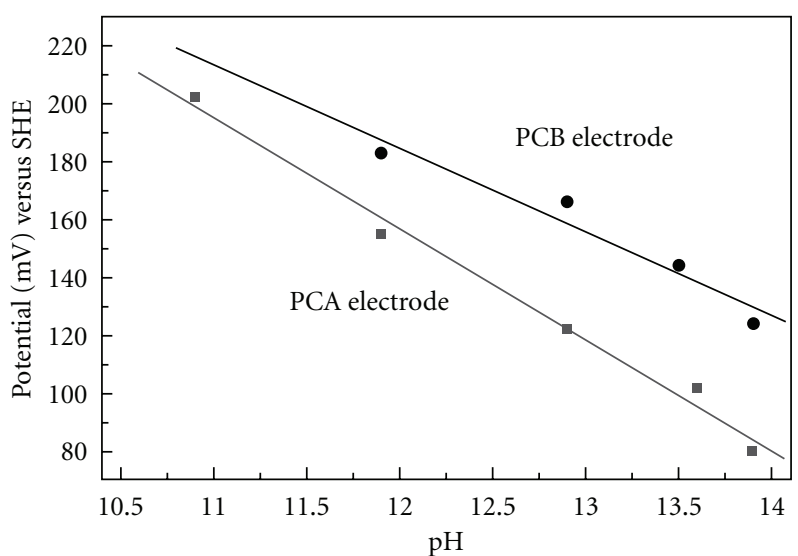

FIGURE 6: Plots of the oxygen reduction rest potentials as a function of electrolyte $\mathrm{pH}$ for the $\mathrm{PC}$ electrodes in oxygen-saturated $\mathrm{KOH}$ electrolyte of constant ionic strength maintained by dilution with $1 \mathrm{M} \mathrm{KCl}$.

TABLE 1: Calculated dependence of the rest potential (open-circuit potential) on the hydroxyl anion concentration, and the oxygen partial pressure for oxygen reduction for the PC electrodes in $\mathrm{KOH}$ electrolyte.

\begin{tabular}{lccc}
\hline Electrode & $n$ & $m^{\prime}( \pm 0.1)$ & $p^{\prime}( \pm 0.1)$ \\
\hline & 1 & 0.6 & 0.5 \\
PCA & 2 & 1.3 & 0.9 \\
$E_{r}^{0}=80 \mathrm{mV}$ versus SHE & 3 & 1.9 & 1.4 \\
& 4 & 2.6 & 1.9 \\
\hline & 1 & 0.5 & 0.2 \\
PCB & 2 & 0.9 & 0.4 \\
$E_{r}^{0}=130 \mathrm{mV}$ versus SHE & 3 & 1.4 & 0.5 \\
& 4 & 1.9 & 0.7 \\
\hline
\end{tabular}

See (15); $E_{r}$ is the rest potential, and $E_{r}^{0}$ is the standard rest potential; $n$ refers to the possible number of electrons transferred for the proposed equilibrium reaction.

It is also beneficial to examine the data on the observed equilibrium potentials for oxygen reduction on the PCB electrode, the activated electrode, before discussing the probable reaction mechanisms. As determined in Section 3.4 and Table 1, the results indicate that the equilibrium is a twoelectron process and of the equilibrium reactions discussed, only (20) gives the correct dependence of the equilibrium potential on $\mathrm{pH}$ and $\left[\mathrm{O}_{2}\right]$ for these electrodes. Independent of the kinetic data, these results would indicate that oxygen reduction on the $\mathrm{PCB}$ electrode is a two-electron process, yielding one $\mathrm{OH}^{-}$and the peroxide anion $\mathrm{HO}_{2}{ }^{-}$instead of the four-electron reduction of oxygen to four $\mathrm{OH}^{-}$anions. However, the kinetic data dispute this conclusion since the reaction order with respect to oxygen was determined to be approximately $1 / 3$ for oxygen reduction on this electrode. No two electron mechanism yielding the peroxide anion or molecule and a reaction order with respect to oxygen of $1 / 3$ can be written unless a totally illogical assumption is made. One would have to assume that the oxygen to oxygen bond in the diatomic molecule is broken in a step preceding the 
rate-determining step and then reformed to yield a peroxide anion in the rate-determining step (RDS) or a subsequent step. Such a possibility is considered improbable due to the large irreversibility of oxygen reduction which is generally attributed in the literature to the low exchange current density and the difficulty of breaking the oxygen to oxygen bond. Isotopic investigations of the peroxide oxygen couple, which yields (20) by Davies et al. [45], proved that all the peroxide anion oxygen originated from gaseous oxygen and that the oxygen to oxygen bond is not actually broken in the formation of the peroxide anion. It has also proved to be impossible to write a two-electron mechanism which also yields the correct transfer coefficient and the correct order of the reaction with respect to $\left[\mathrm{OH}^{-}\right]$, in addition to the correct reaction order with respect to $\left[\mathrm{O}_{2}\right]$.

The only way to account for both the observed equilibrium potential dependence and the kinetics is to assume that the equilibrium potential for oxygen reduction on the PCB electrode is a mixed potential. If two separate reactions are occurring on an electrode surface, one cathodic and one anodic, then the potential at which the currents are equal and cancel each other, to yield a net current of zero, is called a mixed potential.

Here, it is suggested that the most probable cause for the anodic reaction is the oxidation of peroxide anions at the inactive PCA sites. The rest potentials for oxygen reduction on the PCB electrodes were approximately $50 \mathrm{mV}$ to $60 \mathrm{mV}$ anodic to the equilibrium potential for oxygen reduction established on the PCA electrodes. The equilibrium reaction on the pure polymer carbon sites was attributed to reaction (20). If the inactive PC sites on the PCB electrodes are considered to be equivalent in oxygen reduction activity to the carbon sites on the PCA electrodes, then this equilibrium could be considered as representing the reaction occurring on the inactive sites of the PCB electrodes. Since the potentials established on these active electrodes by the oxygen reduction kinetics could be anodic to the established equilibrium potentials of the inactive pure PC sites (established from the PCA electrodes), then a net anodic overpotential could exist at these inactive sites. In summary, the $\mathrm{O} 2 / \mathrm{HO}_{2}{ }^{-}$redox reactions occur at the inactive sites; the $\mathrm{O}_{2} / \mathrm{OH}^{-}$reduction and the $\mathrm{HO}_{2}{ }^{-} / \mathrm{O}_{2}$ oxidation occur at the active sites. In other words, the inactive sites have a key role for the anodic peroxide oxidation, and the active sites have a key role for the cathodic oxygen reduction. Thus, if any peroxide anions adsorbed at these inactive sites, they would be preferentially oxidised to $\mathrm{O}_{2}$ by reaction with $\mathrm{OH}^{-}$. If $\mathrm{HO}_{2}{ }^{-}$intermediates are produced by the reduction of oxygen at the active sites, then the possibility exists for the surface migration of at least a portion of these intermediates to the inactive sites. Alternatively, it could be more probable that the peroxide anions are formed on similar to PCA electrode sites and that their decomposition would preferably be occurring on the excessive active sites of the PCB electrode surface. Depending on the overall potential of the electrode, these intermediates could then be oxidised at the inactive sites. At the potential at which this oxidation of surfacemigrated intermediates at the inactive sites is equal in rate to the complete oxygen reduction occurring at the active sites,

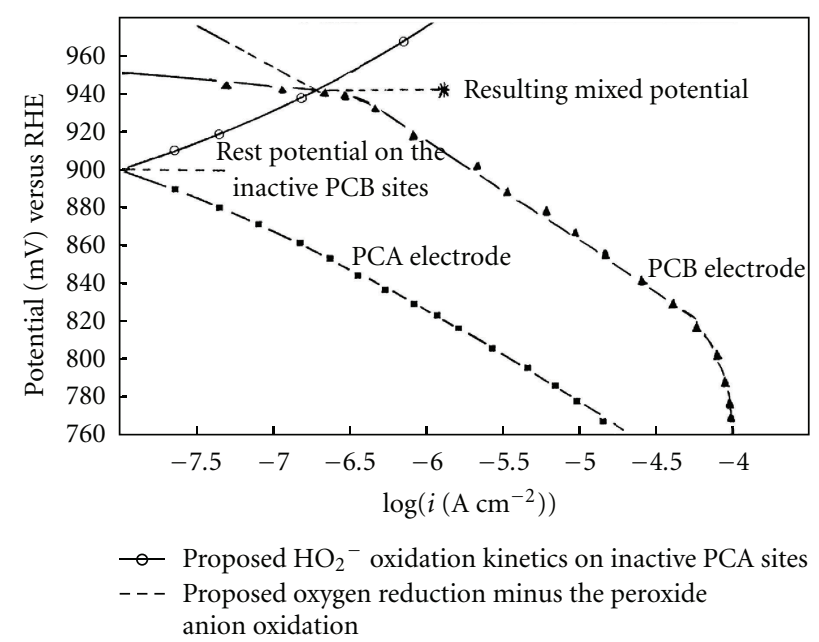

FIGURE 7: The creation of the oxygen reduction rest potential at PCB electrodes by a mixed potential in oxygen-saturated $\mathrm{KOH}$ electrolyte at $\mathrm{pH}$ 13.9.

the net current density would drop to zero. This would be the established rest potential. Such a possibility is illustrated by the data presented in Figure 7. The cathodic reduction data for an active (PCB) and an inactive (PCA) electrode is plotted in the form of potential, $E_{\mathrm{he}}$, as a function of $\log i$. In addition, the expected oxidation curve for the peroxide anion on the electrode (or the inactive PC sites) is drawn as calculated from the reduction data and the equilibrium responsible for the oxygen reduction on the PCA electrodes.

The expected transfer coefficient $\left(\alpha_{a}\right)$ for the oxidation of the peroxide anion $\left[\mathrm{HO}_{2}^{-}\right]$by $\mathrm{OH}^{-}$can be calculated from the following equation derived by Bockris and Reddy [46]:

$$
\alpha_{a}+\alpha_{c}=\left(\frac{n}{v}\right)
$$

In this equation, the number of electrons transferred in the net equilibrium reaction, $n$, is 2 , the number of times the expected RDS is expected to occur for the complete 2 electron transfer ( $\nu$, the stoichiometric number) will be found to be 1 once the proposed mechanism is discussed, and the transfer coefficient for the oxygen, $\alpha_{c}$, on these inactive carbon sites was found to be 1 . This data gives an expected $\alpha_{a}$ of 1 using (20). Since the anodic and cathodic functions should intersect at the equilibrium potential, then the proposed anodic oxidation of the peroxide anion is drawn in Figure 7. If the inactive sites on the PCB electrodes are assumed to be equivalent to the sites on the PCA electrodes, then the potential at which the oxidation current density of the peroxide anions on the inactive sites is equal but opposite in sign to the reduction current density of the oxygen at the active sites, the net observable current density, would be expected to drop to zero. As illustrated in Figure 7, this predicted behaviour was exactly what occurred experimentally. 


\section{Conclusions}

Before drawing conclusions regarding possible mechanistic paths, it should be noted that only a partial kinetic analysis was performed on two-polymer carbon electrodes, both being interrelated with strong basic similarities. Both differed only in the preparative procedure used, with the alteration of surface sites and the creation of pure electrode surfaces (PCAs) and mixed electrode surfaces (PCBs). For this reason, it was useful to propose a comprehensive reduction mechanism to account for oxygen reduction on these more active and less active electrodes rather than two separate mechanisms totally unrelated to each other. In this manner, it may be possible to account for the differing kinetics as due to minor changes in one or two reaction steps. The possible mechanistic paths were chosen from those presented in paper [2], which lists the kinetic equations and the mechanistic criteria.

The kinetics of oxygen reduction on the PCA electrodes were found in Section 3.5 to obey the ideal rate law (17), in the $\mathrm{pH}$ range 13.9 to $10.9, \mathrm{KOH}$ electrolyte. The resulting overall equilibrium responsible for the equilibrium potential was found to be (20) (Section 3.6).

The kinetics are indicative of a nonelectrochemical RDS in which an electron transfer step precedes it and is in equilibrium or in a steady state. The determination of the Tafel slope would also be indicative on this issue. The overall mechanism has to yield the net two-electron reduction previously discussed. In order to give the observed kinetics, it is necessary that the first electron transfer step involves the formation of an adsorbed $\mathrm{O}_{2}{ }^{-}$intermediate either during or following the adsorption of an $\mathrm{O}_{2}$ molecule. The probable mechanisms which obey these restrictions are presented. The $\mathrm{RDS}$ which yields the correct reaction kinetics is indicated for each mechanism.

\section{Mechanism A:}

$$
\begin{aligned}
& \mathrm{O}_{2}+\mathrm{M}+\mathrm{e}^{-} \leftrightarrows \mathrm{MO}_{2}{ }^{-} \\
& \mathrm{MO}_{2}{ }^{-}+\mathrm{MH}_{2} \mathrm{O} \leftrightarrows \mathrm{MOH}+\mathrm{MO}_{2} \mathrm{H}^{-} \quad \mathrm{RDS} \\
& \mathrm{MO}_{2} \mathrm{H}^{-} \leftrightarrows \mathrm{M}+\mathrm{HO}_{2}^{-} \\
& \mathrm{MOH}+\mathrm{e}^{-} \leftrightarrows \mathrm{M}+\mathrm{OH}^{-} .
\end{aligned}
$$

Mechanism B, where $M^{*}$ refers to an active site:

$$
\begin{aligned}
& \mathrm{O}_{2}+\mathrm{M}+\mathrm{e}^{-} \leftrightarrows \mathrm{MO}_{2}^{-} \\
& \mathrm{MO}_{2}^{-}+\mathrm{M}^{*} \leftrightarrows \mathrm{M}+\mathrm{M}^{*} \mathrm{O}_{2}{ }^{-} \quad \mathrm{RDS} \\
& 2 \mathrm{M}^{*} \mathrm{O}_{2}{ }^{-}+\mathrm{H}_{2} \mathrm{O} \leftrightarrows \mathrm{MO}_{2}+\mathrm{M}^{*} \mathrm{O}_{2} \mathrm{H}^{-}+\mathrm{OH}^{-} \\
& \mathrm{M}^{*} \mathrm{O}_{2} \mathrm{H}^{-} \leftrightarrows \mathrm{M}^{*}+\mathrm{HO}_{2}^{-}
\end{aligned}
$$

Mechanism C:

$$
\begin{aligned}
& \mathrm{O}_{2}+\mathrm{M}+\mathrm{e}^{-} \leftrightarrows \mathrm{MO}_{2}^{-} \\
& \mathrm{MO}_{2}{ }^{-}+\mathrm{MOH} \leftrightarrows \mathrm{MO}_{2} \mathrm{H}^{-}+\mathrm{MO} \quad \mathrm{RDS} \\
& \mathrm{MO}_{2} \mathrm{H}^{-} \leftrightarrows \mathrm{M}+\mathrm{HO}_{2}^{-} \\
& \mathrm{MO}+\mathrm{H}_{2} \mathrm{O}+\mathrm{e}^{-} \leftrightarrows \mathrm{MOH}+\mathrm{OH}^{-}
\end{aligned}
$$

Mechanism D:

$$
\begin{aligned}
& \mathrm{O}_{2}+\mathrm{M}+\mathrm{e}^{-} \leftrightarrows \mathrm{MO}_{2}{ }^{-} \\
& \mathrm{MO}_{2}{ }^{-}+\mathrm{H}_{2} \mathrm{O} \leftrightarrows \mathrm{MO}_{2} \mathrm{H}+\mathrm{OH}^{-} \quad \mathrm{RDS} \\
& \mathrm{MO}_{2} \mathrm{H}+\mathrm{e}^{-} \leftrightarrows \mathrm{M}+\mathrm{HO}_{2}{ }^{-} .
\end{aligned}
$$

Mechanism B was suggested by Taylor and Humffray [37] who also postulated the RDS to be the surface diffusion of adsorbed $\mathrm{O}_{2}{ }^{-}$intermediates to active sites. This mechanism would seem to be unlikely since step (24c) represents a trimolecular process. However, the surface diffusion step from an inactive site to an active site is a plausible RDS and could be inserted into mechanisms A, C, or D. Yet such a RDS would be expected to produce a dependence of the current density on agitation of the electrolyte, but such a dependence was not observed in this research nor in other results in the literature $[12,38,47]$. Mechanism C is proposed by the authors but is considered to be unlikely since the qualitative analysis of the voltammograms (not shown here) indicated a low coverage of oxygen-containing redox groups on the surface (such as $\mathrm{MOH}$ ). Mechanisms A and D have been suggested by Apple and Appleby et al. $[12,47]$ from extensive studies of oxygen reduction on carbon materials in alkaline electrolyte [2]. Mechanism A has also been proposed by many other workers (see [2]) in their extensive studies on oxygen reduction on $\mathrm{Pt}, \mathrm{Rh}, \mathrm{Ag}$, and so forth, in acid or alkaline electrolytes whenever peroxide was the reaction product. However, studies by Damjanovic et al. [48-50] contradict those studies favouring a coupled-electron proton transfer rather than a separated electron transfer as given in (23a). Thus, it is clear that there is an urgent need to resolve such contradictions in order to understand the charge transfer sequence of electrochemical oxygen reduction. The first three steps of mechanism D were suggested by Hurlen et al. [51] to account for oxygen reduction to peroxide anion on silver electrodes in alkaline electrolytes. It is then impossible to positively distinguish between mechanisms A or $\mathrm{D}$ as responsible for the kinetics. It should be noted, however, that Damjanovic et al. [50] proposed in their rotating ring-disc studies of oxygen reduction on $\mathrm{Pt}$ in acid or alkaline electrolytes that the $\mathrm{HO}_{2}$-adsorbed intermediate does not result in the formation of peroxide anion. Such an intermediate was used in the mechanisms to explain the kinetics of oxygen reduction in which no peroxide anions at all were detected by the ring-disc technique, and the overall reduction was a four-electron process. If this assumption is correct, then step (26c) in mechanism D would be improbable since it proposes the formation of an $\mathrm{HO}_{2}{ }^{-}$ 
from an adsorbed $\mathrm{HO}_{2}$ intermediate. For this reason and the fact that mechanism A has received more general support by previous investigators, mechanism $\mathrm{A}$ is assumed to be more correct, that is, the more probable to explain present results, followed by mechanism $\mathrm{D}$, to explain oxygen reduction on the electrode in alkaline electrolyte. Mechanism A with step (23b) as the RDS gives the following predicted kinetics:

$$
i=k_{2} K_{1}\left[\mathrm{O}_{2}\right] \exp \left[-\frac{F E}{\mathrm{RT}}\right] \text {. }
$$

The concentration of vacant sites $[\mathrm{M}]$ and adsorbed water $\left[\mathrm{MH}_{2} \mathrm{O}\right]$ are assumed to be constant and included in $k_{2}$.

Using the mechanisms described in paper [2] and the conclusions presented previously on the observed opencircuit potentials, it was tried to establish a reduction mechanism to account for the kinetics of oxygen reduction on the PCB electrode.

In the open literature, there are essentially three classes of proposed mechanisms for oxygen reduction. Some mechanistic paths use only oxide intermediates. Other paths use peroxide intermediates with no aid from absorbed $\mathrm{OH}$ groups while some paths use peroxide intermediate in addition to catalysis by adsorbed $\mathrm{OH}$ groups.

As presented in Section 3, the following ideal rate law holds for oxygen reduction on the PCB electrode in the $\mathrm{pH}$ range of 13.9 to 11.9 ( $\mathrm{KOH}$ electrolyte, constant ionic strength):

$$
i=K\left[\mathrm{OH}^{-}\right]^{-1 / 2}\left[\mathrm{O}_{2}\right]^{1 / 3} \exp \left[-\frac{F E}{\mathrm{RT}}\right] .
$$

No $\mathrm{pH}$-induced change was detected for oxygen reduction on this electrode.

Of the mechanisms presented, only the calculated kinetics for the following mechanism (see Table 18 of [2]) approximates simultaneously the observed kinetics represented by (27) and (28) for oxygen reduction on the PCA and PCB electrodes; respectively,

$$
\begin{aligned}
& \mathrm{M}+\mathrm{O}_{2}+\mathrm{e}^{-} \leftrightarrows \mathrm{MO}_{2}^{-} \\
& \mathrm{MH}_{2} \mathrm{O}+\mathrm{MO}_{2}^{-} \leftrightarrows \mathrm{MOH}+\mathrm{MO}_{2} \mathrm{H}^{-} \\
& \mathrm{MO}_{2} \mathrm{H}^{-} \leftrightarrows \mathrm{MO}+\mathrm{OH}^{-} \\
& \mathrm{MO}+\mathrm{MH}_{2} \mathrm{O} \leftrightarrows 2 \mathrm{MOH} \\
& \mathrm{MOH}+\mathrm{e}^{-} \leftrightarrows \mathrm{M}+\mathrm{OH}^{-}
\end{aligned}
$$

If step (29b) is considered the RDS, the calculated rate equation is

$$
i=k_{2} K_{1}\left[\mathrm{MH}_{2} \mathrm{O}\right][\mathrm{M}]\left[\mathrm{O}_{2}\right] \exp \left[-\frac{F E}{\mathrm{RT}}\right],
$$

which agrees with (27) for the PCA electrode. If step (29e) is considered the RDS, then the calculated rate equation can be written:

$$
\begin{aligned}
i= & K_{5}\left\{K_{4} K_{3} K_{2} K_{1}[\mathrm{M}]\left[\mathrm{MH}_{2} \mathrm{O}\right]^{2}\right\}^{1 / 3}\left[\mathrm{OH}^{-}\right]^{-1 / 3}\left[\mathrm{O}_{2}\right]^{1 / 3} \\
& \times \exp \left[-\frac{5 F E}{6 \mathrm{RT}}\right] .
\end{aligned}
$$

This equation gives $\alpha=5 / 6(0.83)$ and $m=-1 / 3(-0.33)$, which do not agree with the observed kinetics $(\alpha=1.02$ $\pm 0.08, m=-0.50 \pm 0.04$ ) represented by (28) for oxygen reduction on the $\mathrm{PCB}$ electrode in the $\mathrm{pH}$ range of 13.9 to 11.9. It was also concluded earlier in this paper that the observed open-circuit potential was a mixed potential formed by the anodic oxidation of peroxide anion intermediates and the overall four-electron reduction of oxygen, but it is clear that mechanism $(29 a)-(29 e)$ is not a likely explanation for the observed open-circuit potential (see Table 1). In fact, the observed $m^{\prime}$ and $p^{\prime}$ values were 0.9 \pm 0.1 and $0.4 \pm 0.1$, respectively, and the calculated values based on mechanism (29a)-(29e) are 2 and 1, respectively. These reasons effectively lower the probability that the reduction mechanism (29a)-(29e) can explain the observed mechanistic criteria. Equation (29a) as well as (23a), is also contradicted on a recent article by Qi et al. [52], where these authors performed density functional theory simulations of $\mathrm{O}_{2}$ on $\mathrm{Pt}(111)$ surface finding that all oxygen adsorbates are charge neutral, so the 4 electron transfers always occur concurrently with the 4 proton (hydronium) transfers from the aqueous electrolyte; that is, all electron transfers are proton-coupled, rather than separated transfers. In summary, it is certain that the kinetics cannot be easily studied on the PC electrodes. But, that is a fact that the PCB electrode shows an enhanced activity for oxygen reduction in comparison to the PCA electrode. Extensive elemental surface analysis and determination of any induced structural alteration by the preparation procedure was beyond the scope of this research. Such analysis, complemented by further electrochemical studies, would be necessary to help elucidate the nature of the inactive and active surface sites, and this is being more easily accomplished with further research in progress at the moment, which will be published in the near future. A short and qualitative discussion on the surface sites of the two catalysts, that is, ordered or disordered, and their link to the adsorption and reaction mechanisms would also be beneficial in such a publication.

\section{References}

[1] M. Paucirova, D. M. Drazic, and A. Damjanovic, "The effect of surface coverage by adsorbed oxygen on the kinetics of oxygen reduction at oxide free platinum," Electrochimica Acta, vol. 18, no. 12, pp. 945-951, 1973.

[2] P. S. D. Brito and C. A. C. Sequeira, "Cathodic oxygen reduction on noble metal and carbon electrodes," Journal of Power Sources, vol. 52, no. 1, pp. 1-16, 1994.

[3] L. Liu, J. W. Lee, and B. N. Popov, "Development of ruthenium-based bimetallic electrocatalysts for oxygen reduction reaction," Journal of Power Sources, vol. 162, no. 2, pp. 1099-1103, 2006.

[4] M. Van Brussel, G. Kokkinidis, A. Hubin, and C. BuessHerman, "Oxygen reduction at platinum modified gold electrodes," Electrochimica Acta, vol. 48, no. 25-26, pp. 39093919, 2003.

[5] V. Tripković, E. Skúlason, S. Siahrostami, J. K. Nørskov, and J. Rossmeisl, "The oxygen reduction reaction mechanism on $\operatorname{Pt}\left(\begin{array}{lll}1 & 1 & 1\end{array}\right)$ from density functional theory calculations," Electrochimica Acta, vol. 55, no. 27, pp. 7975-7981, 2010. 
[6] S. Walch, A. Dhanda, M. Aryanpour, and H. Pitsch, "Mechanism of molecular oxygen reduction at the cathode of a PEM fuel cell: non-electrochemical reactions on catalytic $\mathrm{Pt}$ particles," Journal of Physical Chemistry C, vol. 112, no. 22, pp. 8464-8475, 2008.

[7] T. Jacob, "The mechanism of forming $\mathrm{H}_{2} \mathrm{O}$ from $\mathrm{H}_{2}$ and $\mathrm{O}_{2}$ over a Pt catalyst via direct oxygen reduction," Fuel Cells, vol. 6, no. 3-4, pp. 159-181, 2006.

[8] E. B. Yeager, "Dioxygen electrocatalysis: mechanisms in relation to catalyst structure," Journal of Molecular Catalysis, vol. 38, pp. 5-25, 1986.

[9] N. M. Marković, R. R. Adžić, B. D. Cahan, and E. B. Yeager, "Structural effects in electrocatalysis: oxygen reduction on platinum low index single-crystal surfaces in perchloric acid solutions," Journal of Electroanalytical Chemistry, vol. 377, no. 1-2, pp. 249-259, 1994.

[10] D. Qu, "Investigation of oxygen reduction on activated carbon electrodes in alkaline solution," Carbon, vol. 45, no. 6, pp. 1296-1301, 2007.

[11] T. Nagaoka and T. Sakai, "Oxygen reduction at electrochemically treated glassy carbon electrodes," Analytical Chemistry, vol. 58, no. 9, pp. 1953-1955, 1986.

[12] M. Appel and A. J. Appleby, "A ring-disk electrode study of the reduction of oxygen on active carbon in alkaline solution," Electrochimica Acta, vol. 23, no. 11, pp. 1243-1246, 1978.

[13] I. Iliev, J. Mrha, A. Kaisheva, and S. Gamburzev, "Influence of the electrolyte content of oxygen carbon gas-diffusion electrodes on their electro-chemical performance in acid solutions," Journal of Power Sources, vol. 3, no. 3, pp. 245-255, 1978.

[14] I. Kruusenberg, J. Leis, M. Arulepp, and K. Tammeveski, "Oxygen reduction on carbon nanomaterial-modified glassy carbon electrodes in alkaline solution," Journal of Solid State Electrochemistry, vol. 14, no. 7, pp. 1269-1277, 2010.

[15] L. Elbaz, E. Korin, L. Soifer, and A. Bettelheim, "Electrocatalytic oxygen reduction by $\mathrm{Co}$ (III) porphyrins incorporated in aerogel carbon electrodes," Journal of Electroanalytical Chemistry, vol. 621, no. 1, pp. 91-96, 2008.

[16] P. Manisankar and A. Gomathi, "Mediated oxygen reduction at a glassy carbon electrode modified with riboflavin and 9,10anthraquinones," Journal of Power Sources, vol. 150, no. 1-2, pp. 240-246, 2005.

[17] P. Manisankar and A. Gomathi, "Electrocatalysis of oxygen reduction at polypyrrole modified glassy carbon electrode in anthraquinone solutions," Journal of Molecular Catalysis A, vol. 232, no. 1-2, pp. 45-52, 2005.

[18] K. Vaik, A. Sarapuu, K. Tammeveski, F. Mirkhalaf, and D. J. Schiffrin, "Oxygen reduction on phenanthrenequinonemodified glassy carbon electrodes in $0.1 \mathrm{M} \mathrm{KOH}$," Journal of Electroanalytical Chemistry, vol. 564, pp. 159-166, 2004.

[19] R. Jasinski, "Cobalt phthalocyanine as a fuel cell cathode," Journal of The Electrochemical Society, vol. 112, pp. 526-528, 1965.

[20] V. S. Bagotzky, M. R. Tarasevich, K. A. Radyushkina, O. A. Levina, and S. I. Andrusyova, "Electrocatalysis of the oxygen reduction process on metal chelates in acid electrolyte," Journal of Power Sources, vol. 2, pp. 233-240, 1977.

[21] C. Z. Deng and M. J. Dignam, "Sputtered cobalt-carbonnitrogen thin films as oxygen reduction electrocatalysts: II. Electrochemical stability and proposed mechanism," Journal of the Electrochemical Society, vol. 145, no. 10, pp. 3513-3520, 1998.
[22] A. Van Der Putten, A. Elzing, W. Visscher, and E. Barendrecht, "Oxygen reduction on pyrolysed carbon-supported transition metal chelates," Journal of Electroanalytical Chemistry, vol. 205, no. 1-2, pp. 233-244, 1986.

[23] Q. L. Zhao, Z. L. Zhang, L. Bao, and D. W. Pang, "Surface structure-related electrochemical behaviors of glassy carbon electrodes," Electrochemistry Communications, vol. 10, no. 2, pp. 181-185, 2008.

[24] P. J. F. Harris, "Fullerene-related structure of commercial glassy carbons," Philosophical Magazine, vol. 84, no. 29, pp. 3159-3167, 2004.

[25] K. Shi and K.-K. Shiu, "Scanning tunneling microscopic and voltammetric studies of the surface structures of an electrochemically activated glassy carbon electrode," Analytical Chemistry, vol. 74, pp. 879-885, 2002.

[26] A. J. Downard and M. J. Prince, "Barrier properties of organic monolayers on glassy carbon electrodes," Langmuir, vol. 17, no. 18, pp. 5581-5586, 2001.

[27] A. A. Mikhaylova, O. A. Khazova, and V. S. Bagotzky, "Electrocatalytic and adsorption properties of platinum microparticles electrodeposited onto glassy carbon and into Nafion films," Journal of Electroanalytical Chemistry, vol. 480, no. 1-2, pp. 225-232, 2000.

[28] J. S. Field and M. V. Swain, "The indentation characterisation of the mechanical properties of various carbon materials: glassy carbon, coke and pyrolytic graphite," Carbon, vol. 34, no. 11, pp. 1357-1366, 1996.

[29] K. R. Kneten and R. L. McCreery, "Effects of redox system structure on electron-transfer kinetics at ordered graphite and glassy carbon electrodes," Analytical Chemistry, vol. 64, no. 21, pp. 2518-2524, 1992.

[30] R. J. Taylor and A. A. Humffray, "Electrochemical studies on glassy carbon electrodes-II. Oxygen reduction in solutions of high $\mathrm{pH}(\mathrm{pH}>10)$," Journal of Electroanalytical Chemistry, vol. 64, pp. 63-84, 1975.

[31] J. O. M. Bockris, "Kinetics of activation controlled consecutive electrochemical reactions: anodic evolution of oxygen," The Journal of Chemical Physics, vol. 24, no. 4, pp. 817-827, 1956.

[32] D. S. Gnanamuthu and J. V. Petrocelli, Journal of The Electrochemical Society, vol. 114, p. 1036, 1967.

[33] O. E. Mouahid, C. Coutanceau, E. M. Belgsir, P. Crouigneau, J. M. Léger, and C. Lamy, "Electrocatalytic reduction of dioxygen at macrocycle conducting polymer electrodes in acid media," Journal of Electroanalytical Chemistry, vol. 426, no. 1-2, pp. 117-123, 1997.

[34] K. J. Vetter, Electrochemical Kinetics, Academic Press, New York, NY, USA, 1967.

[35] E. Gileadi, Physical Electrochemistry, Wiley-VCH, Weinheim, Germany, 2011.

[36] R. E. Davis, G. L. Horvath, and C. W. Tobias, "The solubility and diffusion coefficient of oxygen in potassium hydroxide solutions," Electrochimica Acta, vol. 12, no. 3, pp. 287-297, 1967.

[37] R. J. Taylor and A. A. Humffray, "Electrochemical studies on glassy carbon electrodes-III. Oxygen reduction in solutions of low $\mathrm{pH}(\mathrm{pH}<10)$," Journal of Electroanalytical Chemistry, vol. 64, no. 1, pp. 85-94, 1975.

[38] E. Yeager, P. Krouse, and K. V. Rao, "The Kinetics of the oxygen-peroxide couple on carbon," Electrochimica Acta, vol. 9, pp. 1057-1070, 1964.

[39] W. G. Berl, "A reversible oxygen electrode," Transactions of the Electrochemical Society, vol. 83, pp. 253-270, 1943. 
[40] W. M. Latimer, The Oxidation States of the Elements and Their Potentials in Aqueous Solutions, Prentice-Hall, New York, NY, USA, 2nd edition, 1952.

[41] S. Basu, Ed., Recent Trends in Fuel Cell Science and Technology, Springer, New York, NY, USA, 1st edition, 2007.

[42] A. J. Appleby, in Modern Aspects of Electrochemistry, B. E. Conway and J. O’M. Bockris, Eds., vol. 9, pp. 369-378, Plenum Press, New York, NY, USA, 1974.

[43] J. Bett, J. Lundquist, E. Washington, and P. Stonehart, "Platinum crystallite size considerations for electrocatalytic oxygen reduction-I," Electrochimica Acta, vol. 18, no. 5, pp. 343-348, 1973.

[44] J. T. Lundquist and P. Stonehart, "Platinum crystallite size effects on oxide formation and reduction parameters-II," Electrochimica Acta, vol. 18, no. 5, pp. 349-354, 1973.

[45] M. O. Davies, M. Clark, E. Yeager, and F. Hovorka, "The oxygen electrode-I. Isotopic investigation of electrode mechanisms," Journal of The Electrochemical Society, vol. 106, pp. 56-61, 1959.

[46] J. O’M. Bockris and A. K. N. Reddy, Modern Electrochemistry 1 \& 2, Plenum Press, New York, NY, USA, 1998.

[47] A. J. Appleby and J. Marie, "Kinetics of oxygen reduction on carbon materials in alkaline solution," Electrochimica Acta, vol. 24, no. 2, pp. 195-202, 1979.

[48] A. Damjanovic, A. Dey, and J. O’M. Bockris, "Electrode kinetics of oxygen reduction on oxide-free platinum electrodes," Electrochimica Acta, vol. 12, no. 6, pp. 615-628, 1967.

[49] A. Damjanovic and V. Brusić, "Oxygen reduction at Pt-Au and Pd-Au alloy electrodes in acid solution," Electrochimica Acta, vol. 12, no. 9, pp. 1171-1184, 1967.

[50] A. Damjanovic, M. A. Genshaw, and J. O’M. Bockris, “The role of hydrogen peroxide in oxygen reduction at platinum in $\mathrm{H}_{2} \mathrm{SO}_{4}$ solution," Journal of The Electrochemical Society, vol. 114, pp. 466-472, 1967.

[51] T. Hurlen, Y. L. Sandler, and E. A. Pantier, "Reactions of oxygen and hydrogen peroxide at silver electrodes in alkaline solutions," Electrochimica Acta, vol. 11, no. 10, pp. 1463-1473, 1966.

[52] L. Qi, X. Qian, and J. Li, "Kinetics of congruent vaporization of ZnO islands," Physical Review Letters, vol. 107, no. 14, Article ID 146101, 4 pages, 2011. 


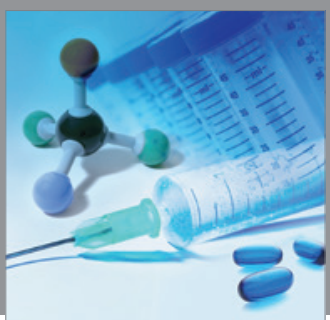

International Journal of

Medicinal Chemistry

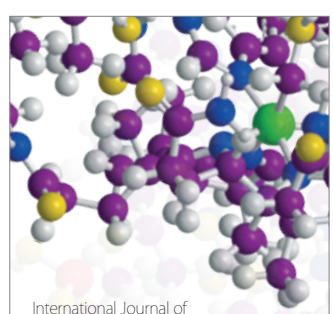

Carbohydrate Chemistry

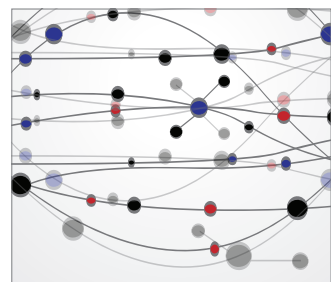

The Scientific World Journal
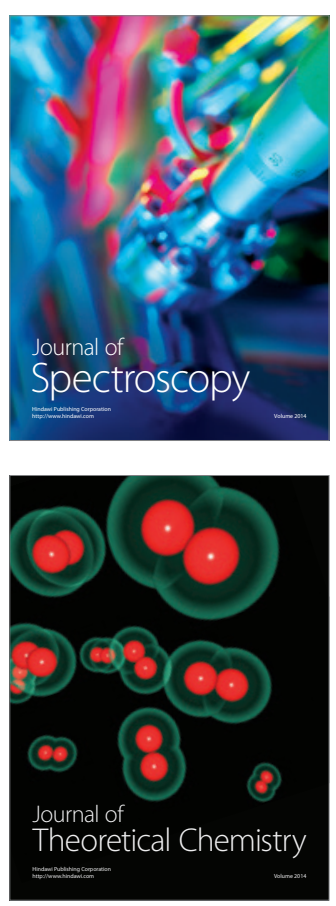
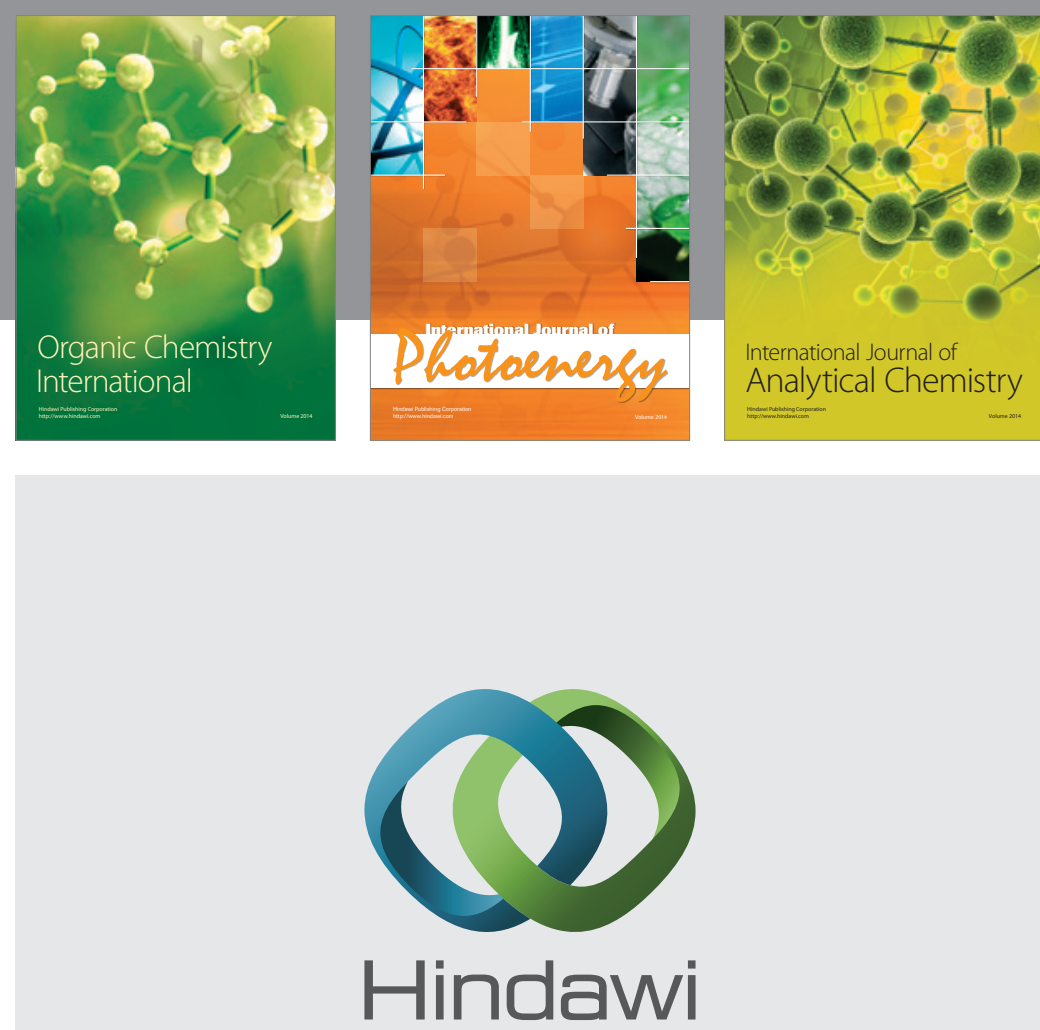

Submit your manuscripts at

http://www.hindawi.com
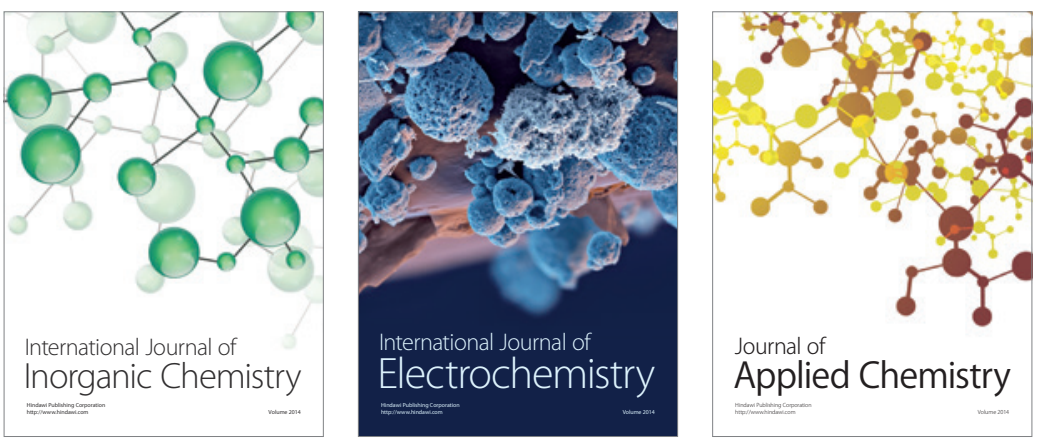

Journal of

Applied Chemistry
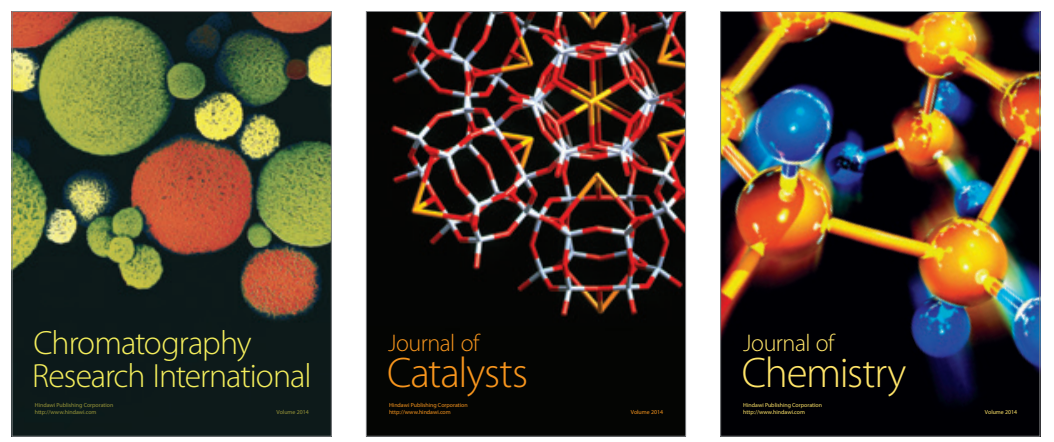
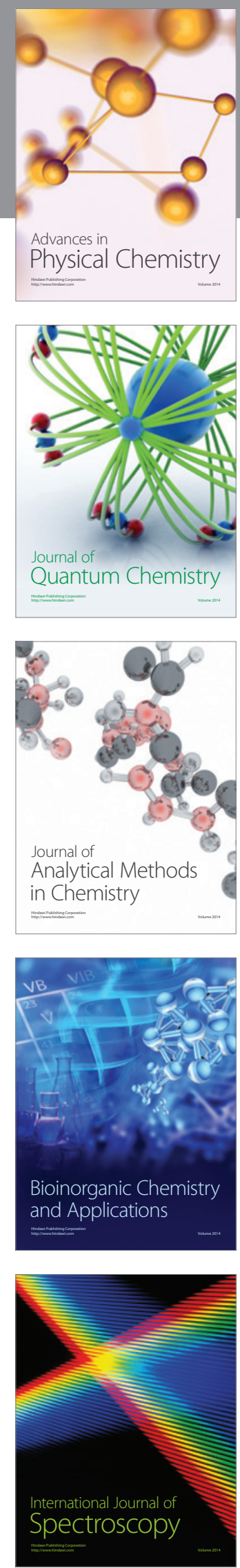